\title{
A Single-end Protection Scheme for Hybrid MMC HVDC Grids Considering the Impacts of the Active Fault Current-limiting Control
}

\author{
Saizhao Yang, Wang Xiang, Member, IEEE, Meng Zhou, Wenping Zuo, Jinyu Wen, Member, IEEE
}

\begin{abstract}
In the hybrid modular multilevel converter (MMC) based high voltage direct current (HVDC) systems, the fault current can be actively suppressed by the converter itself, which endows a smaller requirement for current-limiting reactors (CLR) and a larger time margin for fault detection algorithms, comparing with the half-bridge MMC. But the robustness to fault resistance and noise disturbance of existing boundary protection schemes will be deteriorated with small CLRs. Moreover, the fast response of the fault current-limiting control will change the output DC voltage of hybrid MMC, which affects the fault characteristics and may cause mal-operation of existing protection algorithms. Thus, a single-end protection scheme considering the impacts of the active current-limiting control is proposed for the hybrid MMC based DC grids. The travelingwave characteristics under different fault stages are analyzed to evaluate the impacts of the fault current-limiting control. In addition, a coordination protection strategy versus different fault conditions is adopted to improve reliability. Various cases in PSCAD/EMTDC are simulated to verify that the proposed method is robust to fault resistance, fault distance, power reversal, AC faults, and immune to noise.
\end{abstract}

Index Terms - Hybrid MMC, DC line protection, the active current-limiting control, the forward traveling-wave, fault characteristic analysis.

\section{INTRODUCTION}

With the merits of flexibility and reliability, the modular multilevel converter (MMC) based DC grid using overhead lines transmission is promising to integrate large-scale wind power and solar energy over long-distance [1][2]. There are two main approaches to construct the DC grid topology: 1) The half-bridge (HB) MMC with large-capacity fast-speed DC circuit breakers (DCCB). 2) The fault-tolerant MMC with lowcapacity DCCBs or mechanical disconnectors. For the first approach, the speed of the selective protection scheme should be ultra-fast (less than 3ms) since the HB-MMC is vulnerable to DC faults, which is a great challenge for the protection scheme. On the other hand, the large-capacity DCCBs will increase the cost. Hence, the reliability of the DC fault protection scheme and the cost of DCCBs hamper the

This work is sponsored by the Joint Funds of the National Natural Science Foundation of China (U1766211) and the China Postdoctoral Science Foundation (2019M662622). (Corresponding author: Wang Xiang)

S. Yang, M. Zhou, W. Zuo, J. Wen are with the State Key Laboratory of Advanced Electromagnetic Engineering and Technology, Huazhong University of Science and Technology, Wuhan 430074, China. (e-mail: saizhaoyang@foxmail.com, zhoumeng4077@ foxmail.com, radio.zuo@ foxmail.com, jinyu.wen @hust.edu.cn).

W. Xiang is with the Department of Electronic and Electrical Engineering, University of Strathclyde, Glasgow, G1 1XW, U.K. (e-mail: xiangwang1003@foxmail.com). development of HB-MMC based DC grids [3][4].

Various fault-tolerant MMCs have been proposed to handle the DC faults by taking advantage of converter topologies, such as the self-blocking sub-modules (SM) in [5], the clamping-double SM in [6] and the hybrid MMC in [7]. The hybrid MMC consisting of HB SMs and full-bridge (FB) SMs in series connection can reduce the output DC voltage by negatively inserting the full-bridge FB SMs, thereby suppressing the DC fault current. This approach achieves DC fault ride-through without blocking the SMs and provides reactive power support during DC faults. As a preferred solution to deal with DC faults, the hybrid MMC technology is being applied to China's first three-terminal hybrid HVDC Kunliulong project.

Currently, most of the research is focusing on the fault control design of hybrid MMC, such as the enhanced independent pole control in [8], the additional phase angle control in [9], and the active fault current limiting control (ACLC) in [10]. During DC faults, the fault current rises to a large amplitude within several milliseconds, which imposes great stress on the safe operation of semiconductors. To avoid damage from overcurrent, all hybrid MMCs of DC grids will suppress the fault current by their fault current limiting control. Considering that the short-circuit fault still exists, a selective DC fault detection method is required to isolate the faulty lines, thereby avoiding a shutdown of the entire DC grid. But suitable protection schemes are rarely reported in existing publications. A current differential protection scheme is employed in [11] to achieve selective fault protection. However, the proposed method is easily affected by the line distributed capacitor current and the reliability will be decreased under pole-toground (PTG) faults with high fault resistances. Additionally, these pilot protection schemes are highly dependent on the communication between stations, which is vulnerable to the data code and synchronization errors [12].

For hybrid MMC HVDC systems, existing single-end protection algorithms are originated from the protection schemes of HB-MMC HVDC systems. These protection algorithms rely on large current-limiting reactors (CLR) to provide the boundary effect. As pointed out in [11], for existing protection schemes, large CLRs (over 100mH) are adopted to enable high selectivity and reliability. Various simulation results also demonstrate that $200 \mathrm{mH}$ or larger CLRs are required to guarantee the robustness to large fault resistance and noise disturbance [13]-[16]. However, since the fault current can be suppressed by the ACLC, smaller CLRs are adopted in hybrid MMC HVDC systems, which weaken the boundary effect. On the other hand, for HB-MMC HVDC systems, the speediness of fault protection algorithm is the top 
concern. Due to the fast detection speed, there lacks coordinated protection against different fault conditions. For hybrid MMC HVDC systems, a larger time margin is allowed for fault detection, which provides a potential solution to improve the reliability by the protection coordination. However, there still exist some challenges to be addressed. For example, the protection roles versus different fault conditions need to be well defined. Besides, the operation time and threshold determination of different fault protection criteria need to be coordinated.

Moreover, the impacts of fault current limiting on protection algorithms remain an unsolved problem. During DC fault analysis, the HB MMC is often simplified as a constant voltage source [17][18] at DC side. The fault traveling wave is the main indicator to design the protection algorithm [19]. However, for hybrid MMC based DC grids, the ACLC will quickly decrease the MMC output voltage to respond to the rapid drop of the DC line voltage. Thus, the hybrid MMC is equivalent to an adjustable voltage source at DC side. And the impacts of the ACLC should be considered to design the protection scheme.

To address these challenges, a two-stage coordinated protection strategy is proposed to improve the robustness under different fault conditions and a detailed fault characteristic analysis with ACLC is carried out in this paper. According to different fault stages, the impacts of the ACLC on fault traveling-wave (TW) characteristics are evaluated. Then, the forward TWs under different fault locations are analyzed to design the criterion for fault detection.

The remainder of this paper is structured as follows. Section II introduces the principle of the hybrid MMC and the ACLC. The TW characteristics under different fault stages and locations are analyzed in Section III. Then, the two-stage protection scheme that considers the impacts of the ACLC is proposed in Section IV. Finally, the effectiveness and robustness of the proposed method are verified under extensive cases in Section V and VI.

\section{OPERATING PRINCIPLE OF THE HYBRID MMC AND THE ACTIVE CURRENT-LIMITING CONTROL}

\section{A. Operating Principle of the Hybrid MMC}

Fig. 1 shows the equivalent circuit of the hybrid MMC in single phase view. Each arm contains $N_{F}$ FBSMs and $N_{H}$ HBSMs in series connection. For FBSMs, they can output negative voltages when they are negatively inserted.

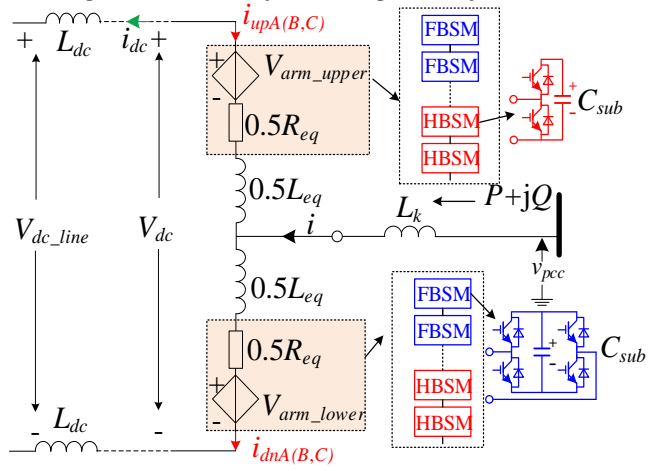

Fig. 1 The single-phase view of hybrid MMC.
Assuming the rated DC voltage is $V_{d c n}$ and the $\mathrm{AC}$ modulation ratio is $M_{a c}$, the output AC voltage $v_{p c c}$ is [8]:

$$
v_{p c c}=M_{a c} \frac{V_{d c n}}{2} \cos \left(\omega t+\varphi_{a c}\right)
$$

Supposing the DC modulation ratio to be $M_{d c}$, the MMC output DC voltage $V_{d c}$ yields:

$$
V_{d c}=M_{d c} V_{d c n}
$$

where $N_{F}$ is equal to $N_{H}$ and $M_{a c}$ is selected to be 0.9 . According to [8], $M_{d c}$ is ranging from -0.1 to 1 . Thus, the MMC output DC voltage $V_{d c}$ satisfies:

$$
-0.1 V_{d c n} \leq V_{d c} \leq V_{d c n}
$$

As can be seen from equations (1)-(3), the hybrid MMC can operate normally with lower output DC voltages and the controls between AC side and DC side are independent.

\section{B. The Principle of the Active Current-limiting Control}

The diagram of a typical active current-limiting control (ACLC) for the hybrid MMC is depicted in Fig. 2 [10]. In Fig. 2, per-unit values are adopted to design the ACLC so that the system parameters have no impacts on the controller. For example, $V_{d c r e f}$ is the DC voltage reference of the constant DC voltage control and it is a per-unit value. $V_{d c p u}\left(V_{d c p u}=V_{d c} / V_{d c n}\right)$ is the per-unit value of measured DC voltage.

Compared with the HB MMCs, the hybrid MMCs have more control freedoms. To guarantee the sub-module capacitor voltage balance during DC faults, the $d$-axis $\left(M_{d}\right) \mathrm{AC}$ control loop adopts the average capacitor voltage control. For $q$-axis $\left(M_{q}\right)$, the reactive power control is employed.

Under normal operation, the DC control loop $\left(M_{d c}\right)$ adopts the constant DC voltage control (mode I) or the active power control (mode III). In the event of DC faults, to suppress the fault current and reduce the breaking capacity of DCCBs, the DC current control (mode II) is adopted. $I_{\text {dcref }}$ is selected to be 0 . The criterion to select mode II selection is:

$$
\frac{d V_{d c}}{d t}<D V_{s e t}
$$

where $V_{d c}$ is the MMC output DC voltage and $D V_{\text {set }}$ is the threshold for the mode II selection.

As shown in Fig. 2, to achieve fast fault isolation and postfault recovery, the voltage feed-forward control $K_{F F} * V_{d c p u}$ is adopted to quickly respond to the rapid drop of the DC voltage [10]. The voltage feed-forward control will adjust the DC component of the arm voltage, thereby decreasing the DC fault current.

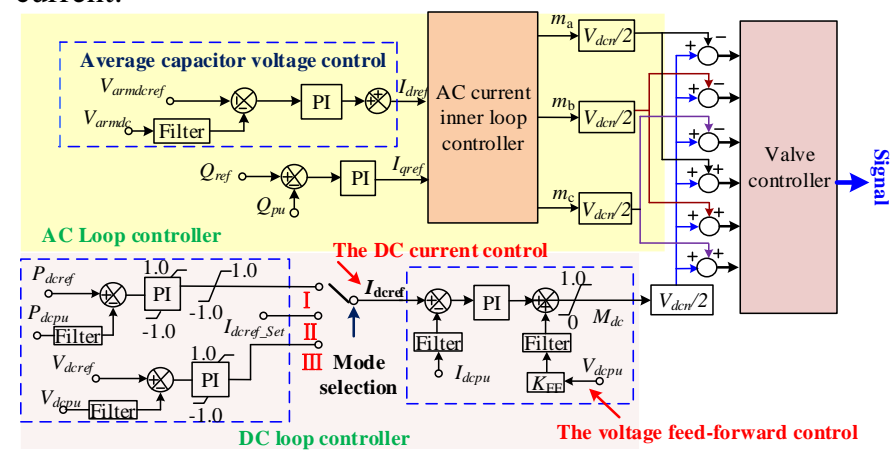

Fig. 2 The active fault current-limiting control diagram of the hybrid MMC.

\section{ANALYSIS OF TW CHARACTERISTICS UNDER DIFFERENT} FAULT STAGES AND LOCATIONS 
A. The TW Characteristic Analysis under Different Fault Stages

Under DC faults, a negative voltage source $-V_{0}$ is superimposed on the fault point [20]. The voltage $-V_{0}$ propagates toward the transmission line (OHL) terminal and is reflected at the current-limiting reactor, as shown in Fig. 3.

The change of the DC line voltage $V_{d c_{-} \text {line }}\left(\Delta V_{d c_{-} \text {line }}\right)$ can be expressed as:

$$
\Delta V_{d c_{-} \text {line }}=V_{f}\left(t-\frac{x}{v}\right)+V_{b}\left(t+\frac{x}{v}\right)
$$

where $V_{f}$ and $V_{b}$ represent the forward TW in the positive direction and the backward TW in the negative direction of $x$ axis respectively. The specific TW analysis under different fault stages will be conducted as follows.

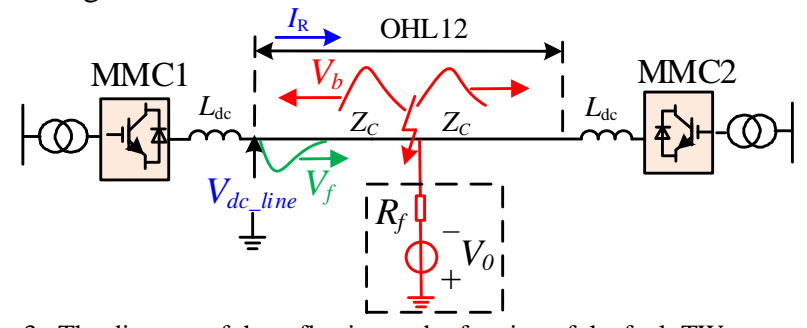

Fig. 3. The diagram of the reflection and refraction of the fault TW.

\section{1) First stage: the initial TW propagation}

Denote the first negative backward TW from the fault point as $V_{b}^{l}$. The initial backward TW $V_{b}^{l}$ will be reflected at the terminal of OHL. The reflected TW is forward and denoted as $V_{f}^{l}$. The initial TWs $V_{b}^{l}$ and $V_{f}^{l}$ can be calculated as [21]:

$$
\left\{\begin{array}{c}
V_{f}^{l}=\left[\frac{2 Z_{C}}{Z_{C}+Z_{e q}} \times e^{\frac{-t}{T_{L}}}+\frac{Z_{e q}-Z_{C}}{Z_{C}+Z_{e q}}\right] \times V_{b}^{l} \\
V_{b}^{l}=\frac{Z_{C} \times\left(-V_{0}\right)}{Z_{C}+2 R_{f}} e^{-\gamma x}
\end{array}\right.
$$

where $R_{f}$ and $Z_{C}$ represent the fault resistance and the waveimpedance of the OHL, respectively. $x$ is the fault distance. $\gamma$ is the propagation coefficient, which represents the attenuation characteristics of OHL. For two-terminal systems, $Z_{e q}$ represents the equivalent impedance of MMC. For meshed DC grids, considering multiple parallel lines connected to the same DC busbar, the equivalent impedance of parallel lines connected to the same DC busbar should also be accounted into $Z_{\text {eq. }} . T_{L}$ is the time constant, which can be expressed as:

$$
T_{L}=\frac{L_{d c}}{Z_{C}+Z_{e q}}
$$

Based on equations (5)-(7), the change of the DC line voltage $\left(\Delta V_{d c_{-} \text {line }}\right)$ can be obtained as:

$$
\Delta V_{d c_{-} \text {line }}=V_{f}^{l}+V_{b}^{l}=\left[\frac{Z_{C}}{Z_{C}+Z_{e q}} \times e^{\frac{-t}{T_{L}}}+\frac{Z_{e q}}{Z_{C}+Z_{e q}}\right] \times 2 V_{b}^{l}
$$

As can be seen from equation (8), the DC line voltage $V_{d c \_l i n e}$ drops rapidly once TW $V_{b}^{l}$ arrives at the terminal of the OHL.

Denote the time when the initial backward TW $V_{b}^{l}$ arrives at the terminal of OHL as $t_{l}$. With the delay for the voltage derivative measurement, the reference of the DC current $I_{d c r e f}$ shifts to zero. Meanwhile, the voltage feed-forward control perceives the rapid drop of DC voltage. At $t_{2}$, the ACLC consisting of the DC current control and the feed-forward control starts to respond to the change of the DC voltage. After the response delay of the pole controller, $M_{d c}$ is adjusted quickly so as to reduce the DC component of the arm bridge voltage $V_{\text {armdc }}$ at $t_{3}$. Subsequently, the valve controller acts to insert some FBSMs negatively, thereby decreasing the MMC output voltage at $t_{4}$. The overall response process of the ACLC is depicted in Fig. 4.

The total response delay for the ACLC $\left(t_{4}-t_{1}\right)$ is ranging from $0.5 \mathrm{~ms}$ to $1 \mathrm{~ms}$ [10], where the total response means the interval from ACLC activation to the reduction of $M_{d c}$. The PI parameters of the controllers have an impact on the response delay $\left(t_{4}-t_{1}\right)$. Due to plenty of energy-storage elements (the line inductances and capacitors) and the current-limiting reactors (CLRs), the voltage $V_{d c_{-} \text {line }}$ will not be affected by the ACLC immediately. After a short delay, the ACLC affects the DC line voltage $V_{d c \_l i n e}$ at $t_{5}$, leading to the further drop of the voltage $V_{d c_{-} \text {line. }}$ The time interval between $t_{l}$ and $t_{5}$ is ranging from $1 \mathrm{~ms}$ to $2 \mathrm{~ms}$ and it is defined as the initial TW stage.

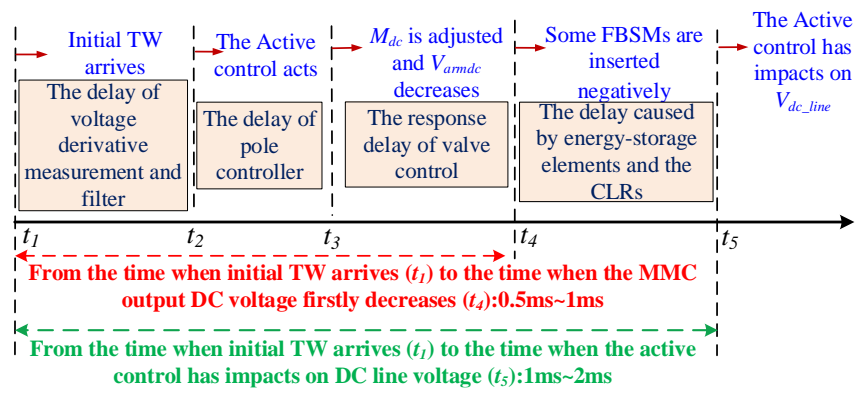

Fig. 4. The overall response process of the active current-limiting control.

During the initial TW stage $\left(t_{1} \sim t_{5}\right)$, due to the response delay, the influence of ACLC is negligible. The fault characteristics are predominantly determined by the reflection and refraction of the TWs. As shown in Fig. 5, the initial forward TW $V_{f}^{l}$ propagates towards MMC2 and is reflected again at the fault point. The reflected wave will travel back to the terminal of OHL while the refracted wave will continue to propagate towards MMC2. Thus, there exist multiple TW reflections and refractions during the initial TW stage.

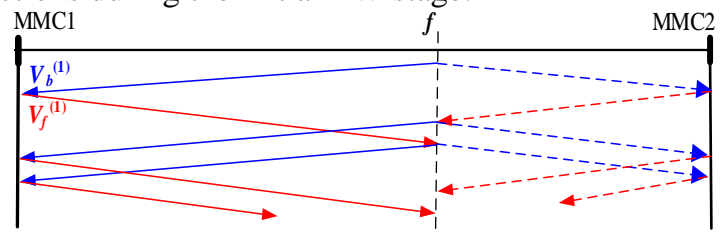

Fig. 5. The diagram of multiple traveling-wave reflections and refractions.

Considering that the dispersion effect of OHL on TWs and the amplitude of the reflection coefficient is smaller than 1, the initial TWs $\left(V_{f}^{l}\right.$ and $\left.V_{b}^{l}\right)$ are dominant.

2) Second stage: the impact of ACLC

During the second stage, the ACLC will affect the fault characteristics.

During DC faults, the upper and lower arms of hybrid MMC can be equivalent as a controllable voltage resource, as shown in Fig. 6. Where $I_{d c}$ is the DC current and $I_{d c n}$ is the rated DC current. $V_{d c_{-} \text {line }}$ is the DC line voltage at the terminal of the OHL. $L_{e q}$ and $R_{e q}$ are the equivalent inductance and resistance of the MMC respectively. $R_{0}$ and $L_{0}$ are the arm bridge resistance and arm inductance of MMC, respectively. 


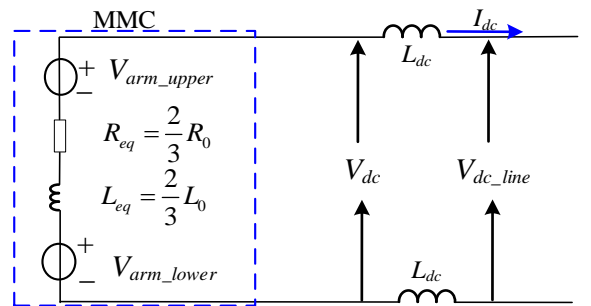

Fig. 6 The equivalent circuit of the hybrid MMC under DC faults.

The MMC output DC voltage $V_{d c}$ can be calculated as:

$$
V_{d c}(s)=2 s L_{d c} I_{d c}(s)+V_{d c_{-} \text {line }}(s)
$$

Based on the equivalent circuit in Fig. 6, it yields,

$$
V_{\text {arm_upper }}(s)+V_{\text {arm_lower }}(s)=\left(s L_{e q}+R_{e q}\right) I_{d c}(s)+V_{d c}(s)
$$

where $V_{\text {arm upper }}$ and $V_{\text {arm lower }}$ are the DC components of the upper and lower arm voltages respectively. They can be calculated as:

$$
V_{\text {arm_upper }}(s)+V_{\text {arm_lower }}(s)=M_{d c}(s) V_{d c n}
$$

Thus, the DC current $I_{d c}$ can be expressed as:

$$
I_{d c}(s)=\frac{M_{d c}(s) V_{d c n}-V_{d c}(s)}{s L_{e q}+R_{e q}}
$$

According to Fig. 2, the block diagram of the ACLC can be obtained, as shown in Fig. 7. We have,

$$
\left(I_{d c r e f}-\frac{I_{d c}}{I_{d c n}}\right)\left(k_{p i}+\frac{k_{i i}}{s}\right)+\frac{K_{F F} V_{d c}}{V_{d c n}}=M_{d c}(s)
$$

where $k_{p i}$ and $k_{i i}$ are the PI parameters of the DC current control in Fig.2. $I_{\text {dcref }}$ is adopted to be 0 . Substituting equation (12) into (13) yields,

$$
\begin{gathered}
-\frac{M_{d c}(s) V_{d c n}-V_{d c}}{\left(s L_{e q}+R_{e q}\right) I_{d c n}}\left(k_{p i}+\frac{k_{i i}}{s}\right)+\frac{K_{F F} V_{d c}}{V_{d c n}}=M_{d c}(s) \\
\text { Let }\left(k_{p i}+\frac{k_{i i}}{s}\right) V_{d c n} /\left[\left(s L_{e q}+R_{e q}\right) I_{d c n}\right] \text { be } k_{l}(s), \text { then (14) can }
\end{gathered}
$$

be obtained as:

$$
\begin{gathered}
M_{d c}(s)=\frac{K_{F F}+k_{l}(s)}{1+k_{l}(s)} V_{d c p u} \\
I_{d c}(s)=\frac{\left(K_{F F}-1\right) V_{d c p u}}{\left(1+k_{l}(s)\right)\left(s L_{e q}+R_{e q}\right)}
\end{gathered}
$$

Substituting equation (16) into (9), we have,

$$
V_{d c}(s)=\frac{s L_{d c}\left(K_{F F}-1\right) V_{d c}(s)}{\left(s L_{e q}+R_{e q}\right)\left(1+k_{l}(s)\right)}+V_{d c_{-} \text {line }}(s)
$$

Let $s L_{d c}\left(1-K_{F F}\right) /\left[\left(s L_{e q}+R_{e q}\right)\left(1+k_{1}(s)\right)\right]$ be $k_{2}(s)$, then it can be obtained as,

$$
V_{d c}(s)=\frac{V_{d c_{-} \text {line }}(s)}{1+k_{2}(s)}
$$

where $K_{F F}<1$. Thus, $k_{2}(\mathrm{~s})>0$.

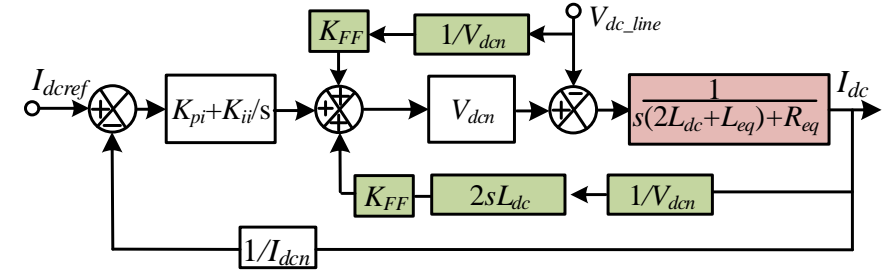

Fig. 7 The block diagram of the ACLC.

Based on the aforementioned analysis, it can be concluded:

1) Equation (16) indicates that the ACLC can be adopted to decrease the amplitude of the fault current.

2) As can be seen in equations (15)(18), there exist deep interactions among the DC modulation ratio $M_{d c}$, the MMC output DC voltage $V_{d c}$ and the DC line voltage $V_{d c_{-} \text {line. To }}$ respond to the rapid drop of the DC line voltage $V_{d c \_l i n e}$ under DC faults, the ACLC will act to reduce the voltage $V_{\text {armdc }}$ quickly by decreasing the DC modulation ratio $M_{d c}$, thereby decreasing the MMC output voltage $V_{d c}$. The reduction of $V_{d c}$ causes a further decrease of the voltage $V_{d c \_l i n e}$.

The voltage feed-forward control perceives the DC voltage drop and acts to accelerate the attenuation of the voltages $V_{d c}$ and $V_{d c \text { _line. }}$ The positive feedback process results in the continuous drop of the DC voltage until the fault steady stage reaches. Thus, the aforementioned DC voltage regulation process is equivalent to injecting a negative voltage forward TW into the OHL, as shown in Fig. 8.

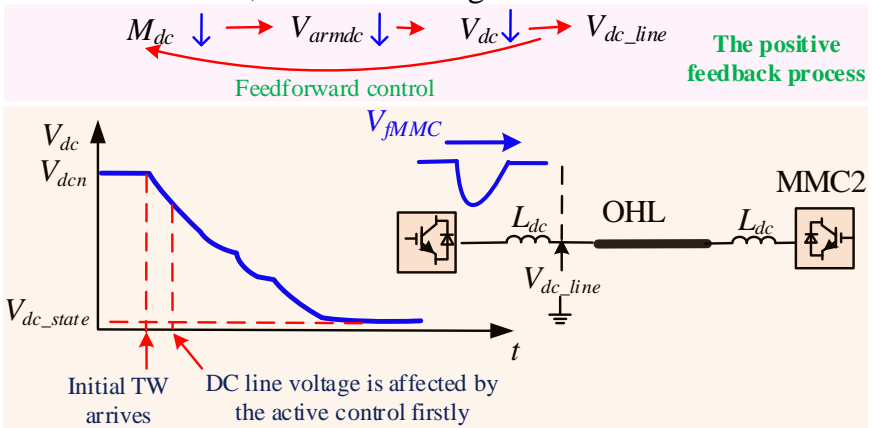

Fig. 8. The diagram of impacts of the ACLC on fault protection.

Thus, considering the impacts of the ACLC, the detected forward TW $V_{f}$ can be expressed as:

$$
V_{f}=V_{f}^{(0)}+\left(-V_{f M M C}\right)
$$

where $V_{f}^{(0)}$ is the forward TW without regard to the impacts of the ACLC. The voltage $-V_{f M M C}$ represents the injected negative equivalent voltage forward TW from the hybrid MMC.

3) As shown in equations (15)(18), in the case of a larger $K_{F F}$, the response of ACLC to DC faults is faster, resulting in the voltages $V_{d c}$ and $V_{d c_{-} \text {line }}$ decreasing more greatly. Therefore, the amplitude of the fault current is smaller. Especially, when $K_{F F}$ is selected to be $1, M_{d c}, V_{d c}$ and $V_{d c_{-} \text {line }}$ have the same attenuation characteristics under DC faults. To be concluded, a larger $K_{F F}$ will bring about larger impacts of ACLC on the fault characteristics.

To verify the impacts of the ACLC on fault characteristics, a positive PTG fault with $100 \Omega$ fault resistance is tested in the hybrid MMC-HVDC and half-bridge MMC-HVDC systems respectively. The system parameters are shown in Section V. The fault is applied in the middle of OHL12 at $2.5 \mathrm{~s}$. The detected forward TW waveforms are shown in Fig. 9. 


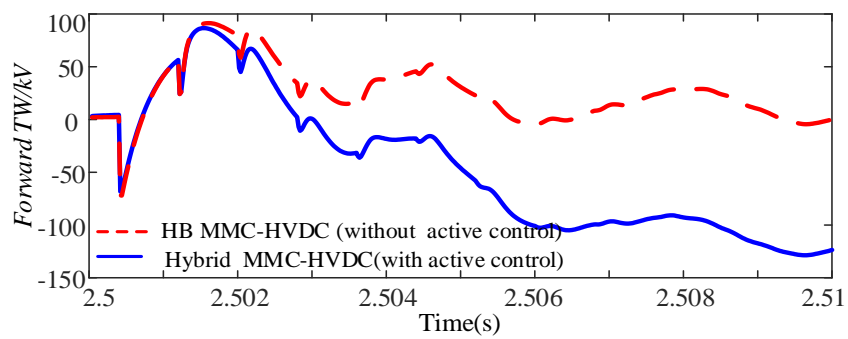

Fig. 9. The forward TW waveforms under different systems.

As can be seen in Fig. 9, for hybrid MMC-HVDC systems, the ACLC will decrease the magnitude of the forward TW. Besides, the response delay of the ACLC is no more than $2 \mathrm{~ms}$, which demonstrates the ACLC has a fast response speed.

In the case of low-impedance faults, the DC line voltage $V_{d c_{-} \text {line }}$ drops rapidly even no active control is employed. In contrast, under high-impedance faults, the voltage drop of DC line voltage is not severe without the ACLC control. Thus, the ACLC affects the TW characteristics under high-impedance faults rather than those under low-impedance faults.

\section{B. The TW Analysis under Different Fault Locations}

Fig. 10 shows the diagram of TW reflection and refraction under different fault locations, where $F_{12}$ is an internal fault while $F_{1}$ and $F_{2}$ are external faults for the relay $\mathrm{CB} 12$. Assuming that the direction from MMC to OHL is positive, $F_{12}$ and $F_{2}$ are forward faults while $F_{1}$ is a backward fault.

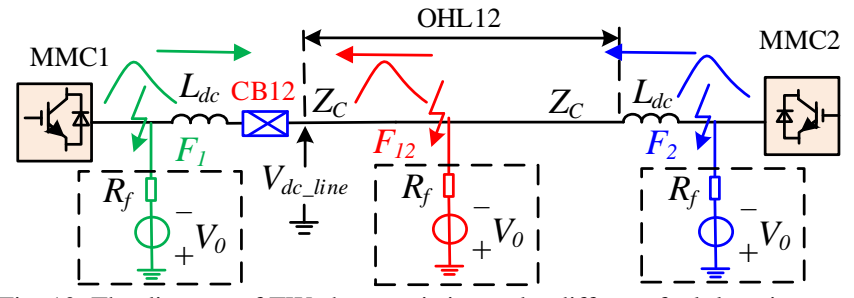

Fig. 10. The diagram of TW characteristics under different fault locations.

\section{1) The TW analysis under backward and forward faults}

For forward faults $\left(F_{12}\right.$ and $\left.F_{2}\right)$, equation (6) points out that the magnitude of the voltage derivative of the initial backward TW $V_{b}^{l}\left(d V_{b}^{l} / d t\right.$, it is negative) is larger than that of the initial forward TW $V_{f}^{l}\left(d V_{f}^{l} / d t\right.$, it is negative). Thus, for forward faults, it can be obtained:

$$
\frac{\min \left(d V_{b}^{l} / d t\right)}{\min \left(d V_{f}^{l} / d t\right)}>1
$$

where $\min ($ ) represents the function that obtains the minimum value.

As shown in Fig. 11, for backward faults $\left(F_{1}\right)$, the forward TW from the fault point propagates towards the measured point $V_{d c_{-} \text {line. }}$. The initial forward TW $V_{f}^{l}$ is reflected at the $\mathrm{OHL}$ terminal close to MMC2. After a delay of $2 l / v$ ( $l$ is the length of OHL12 and $v$ is the TW propagation speed), the reflected wave $V_{b}^{l}$ arrives at the measured point. The initial backward TW $V_{b}^{l}$ can be expressed as:

$$
\left\{\begin{array}{c}
V_{b}^{1}=\Gamma(t) \times V_{f}^{1} \times\left(e^{-\gamma l}\right)^{2} \\
\Gamma(t)=\left[\frac{2 Z_{C}}{Z_{C}+Z_{e q}} \times e^{\frac{-t}{T_{L}}}+\frac{Z_{e q}-Z_{C}}{Z_{C}+Z_{e q}}\right]
\end{array}\right.
$$

Thus, for backward faults, it can be obtained:

$$
\frac{\min \left(d V_{b}^{l} / d t\right)}{\min \left(d V_{f}^{l} / d t\right)} \ll 1
$$

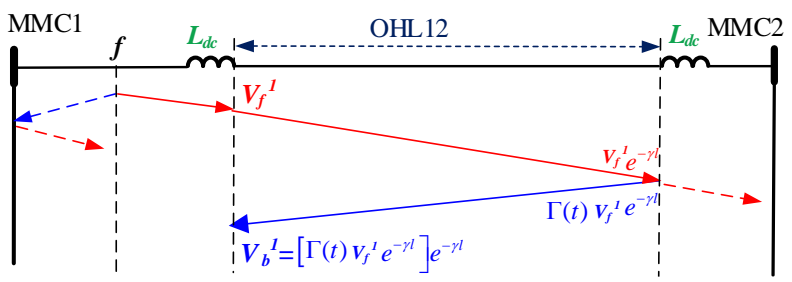

Fig. 11. The diagram of the reflection and refraction under backward faults.

To be concluded, the ratio between $\min \left(d V_{b}^{l} / d t\right)$ and $\min \left(d V_{f}^{l} / d t\right)$ can be adopted to identify backward faults.

2) TW analysis under forward external and internal faults

In the case of a solid fault at $F_{2}$, the detected initial TW at the relay CB12 is [20],

$$
V_{b}^{l}=\frac{Z_{C} \times\left(-V_{0}\right)}{Z_{C}+s L_{d c}} e^{-\gamma x}
$$

As can be seen from equations (6)(23), under the forward external fault, due to the smooth effects provided by the current-limiting reactors, the DC line voltage drops slowly.

Based on equations (15)(18) and the criterion (4), it can be obtained that:

(1) Due to the slow drop of the DC voltage, the DC current control (mode II selection) is activated at a slower speed under the external faults.

(2) The slower drop of the DC line voltage results in the minor reduction of the DC modulation ration $M_{d c}$ and the DC voltage $V_{d c}$, which weakens the impact of the ACLC.

Thus, under a forward external fault $\left(F_{2}\right)$, a negative TW with a smaller amplitude is injected into the OHL. The forward TW $V_{f}$ falls slightly.

However, for a forward internal fault $\left(F_{12}\right)$, due to the rapid drop of the DC line voltage, the DC current control is activated faster. The voltage feed-forward control perceives the rapid drop of the DC line voltage and the $M_{d c}$ is reduced drastically. A negative TW with a larger amplitude is injected into the OHL. Thus, the forward TW drops more greatly. The injected negative equivalent voltage forward TW $\left(-V_{f M M C}\right)$ under different faults can be expressed as:

$$
-V_{f M M C}\left(F_{12}\right)<-V_{f M M C}\left(F_{2}\right)
$$

The detailed comparison of impacts of the ACLC on forward TWs can be concluded, as shown in Table 1.

Table 1 Impacts of the ACLC on forward TWs under different faults

\begin{tabular}{c||c|c|c|c|c}
\hline \multirow{2}{*}{ Fault } & \multicolumn{5}{c}{ The impacts of ACLC on the forward TWs $V_{f}$} \\
\cline { 2 - 6 } & $V_{d c \_l i n e}$ & $V_{d c}$ & $M_{d c}$ & $\begin{array}{c}-V_{f M M C} \\
\text { (negative) }\end{array}$ & $V_{f}$ \\
\hline \hline $\begin{array}{c}\text { Forward } \\
\text { internal faults }\end{array}$ & $\begin{array}{c}\downarrow \\
\text { greatly }\end{array}$ & $\begin{array}{c}\downarrow \\
\text { greatly }\end{array}$ & $\begin{array}{c}\downarrow \\
\text { greatly }\end{array}$ & $\begin{array}{c}\text { A larger } \\
\text { amplitude }\end{array}$ & Smaller \\
\hline $\begin{array}{c}\text { Forward } \\
\text { external faults }\end{array}$ & $\begin{array}{c}\downarrow \\
\text { slowly }\end{array}$ & $\begin{array}{c}\downarrow \\
\text { slowly }\end{array}$ & $\begin{array}{c}\downarrow \\
\text { slowly }\end{array}$ & $\begin{array}{c}\text { A smaller } \\
\text { amplitude }\end{array}$ & Larger \\
\hline
\end{tabular}

As can be seen in Table 1, considering the impacts of the ACLC, the forward TW $V_{f}$ is smaller under internal faults. Thus, the under-voltage criterion of the forward TW can be employed to differentiate external faults and internal faults.

\section{A Two-Stage Fault Protection Scheme CONSIDERING THE IMPACTS OF THE ACLC}


The ACLC of the hybrid MMC allows a longer time window to detect DC faults. To improve the reliability of fault detection, a two-stage coordinated protection strategy is proposed. For the severe internal DC faults with low resistances, the Stage I protection can identify them with ultra-high-speed. For the internal DC faults with higher resistances, the Stage II protection considering the impacts of ACLC is designed to detect the faults.

\section{A. The Design of Stage I Protection: ROCOV with Fast Speed}

With the merits of low computation burden, low sampling frequency, fast detection speed and simple implementation, the rate of change of DC line voltage (ROCOV) is preferred to serve as the main protection [22]. The criterion of ROCOV is as:

$$
\frac{d V_{d c \_l i n e}}{d t}<\Delta
$$

where $V_{d c \_l i n e}$ is the DC line voltage. $\Delta$ is the threshold for ROCOV and it is negative.

To avoid noise disturbance under external faults, the threshold with higher reliability coefficient $k_{\text {rell }}$ is selected to design the criterion of the Stage I protection, which can be expressed as:

$$
\frac{d V_{d c_{\text {_line }}}}{d t}<\Delta_{I}
$$

where $\Delta_{I}$ is the threshold for the Stage I protection.

The Stage I protection is fast and not affected by noise disturbance. However, equation (8) points out that ROCOV is less endurable to fault resistance. Thus, the Stage II protection is required to improve the endurance to fault resistance.

To detect the arrival of the initial fault TW and avoid the noise disturbance under normal state, the threshold with a smaller reliability coefficient $k_{\text {rel }}$ is adopted as the fault startup element to activate the Stage II protection.

$$
\frac{d V_{d c_{-} \text {line }}}{d t}<\Delta_{I I}
$$

where $\Delta_{I I}$ is the threshold for the start-up element of Stage II protection and $\Delta_{I}$ (negative) $<\Delta_{I I}$ (negative).

\section{B. The Design of Stage II Protection: The Impacts of the Active Control Has Been Considered}

Based on the aforementioned analysis, the forward TWs are smaller under internal faults. Thus, the low-voltage criterion using the forward TW has been adopted to detect internal and external faults. To mitigate the impacts of the noise disturbance, the integral process is employed to optimize the low-voltage criterion [23], which can be expressed as:

$$
\Delta V_{f}=\int_{t}^{t+T_{w}} V_{f}<\Delta V_{\text {set }}
$$

where $\Delta V_{\text {set }}$ is the threshold for the low-voltage criterion and $T_{w}$ is selected as $1 \mathrm{~ms}$.

Considering the response delay of the ACLC, a delay $\Delta t_{l}$ is required to calculate the $\Delta V_{f}$. Namely, after the activation of the fault start-up element, wait a delay $\Delta t_{I}$. Then, the forward TW low-voltage criterion calculation is conducted for further detection. To avoid the disturbance of backward faults, the directional element based on criterion (20) is adopted.

From the aforementioned analysis, the overall protection scheme that considers the impacts of the ACLC can be obtained, as depicted in Fig. 12.

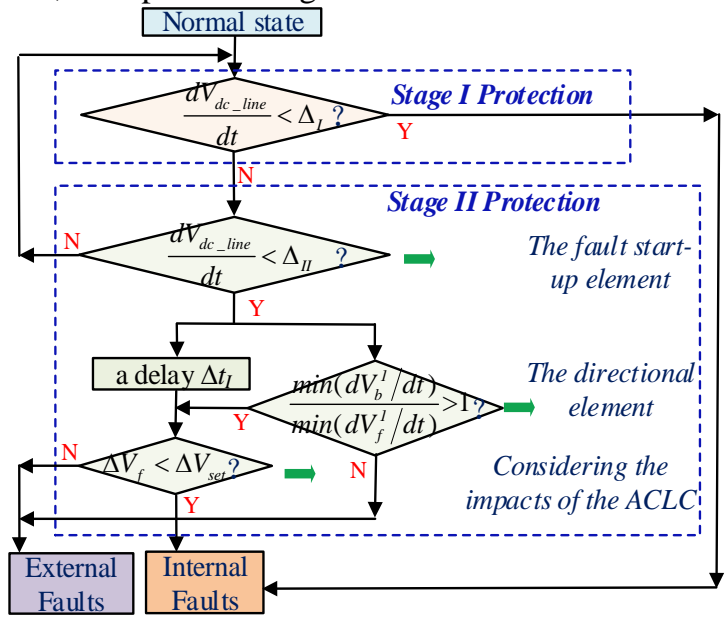

Fig. 12. The overall protection scheme that considers impacts of the ACLC

\section{SIMULATION AND VERIFICATION}

In order to verify the feasibility and effectiveness of the proposed method, a $\pm 500 \mathrm{kV}$ four-terminal hybrid MMC based DC grid is built in PSCAD/EMTDC, as shown in Fig. 13. The overhead line adopts the frequency-dependent model. and the system is a symmetric monopole structure and the other converter parameters are listed in Table 2. MMC3 controls the DC link voltage while other converters control the transmitted power. With the great likelihood of the occurrence, pole-toground faults are the main concern in the simulation. $D_{\text {Vset }}$ for the Mode II selection is adopted to be $-75 \mathrm{kV} / \mathrm{ms}$. Besides, $\Delta t_{I}$ is adopted as 5ms. DCCB adopts the hybrid DCCB topology proposed by ABB [24].

Table 2 Parameters of each converter station

\begin{tabular}{c||cccc}
\hline Converter & MMC1 & MMC2 & MMC3 & MMC4 \\
\hline arm inductance $/ \mathrm{mH}$ & 50 & 50 & 50 & 50 \\
sub-module capacitor $/ \mathrm{mF}$ & 4 & 4 & 8 & 8 \\
sub-module number / $N$ & 200 & 200 & 200 & 200 \\
rated power / MW & 750 & 750 & 1500 & 1500 \\
\hline
\end{tabular}

Based on the methodology to determine the CLRs in [25], the lower limit of CLR ( $L_{d c}^{\text {lower }}$ ) for unblocking HB-MMC systems can be calculated as $269 \mathrm{mH}$. Due to the currentlimiting capacity, the CLRs for hybrid MMC will be smaller. Thus, $L_{d c}^{\text {lower }}$ can be adopted as the upper limit for hybrid MMC based DC systems. Combing the simulation results, 0.1H CLR is adopted to guarantee the safety of converter under DC faults. And this value is sufficient to distinguish a low impedance fault using travelling wave or fast transient based algorithms. 


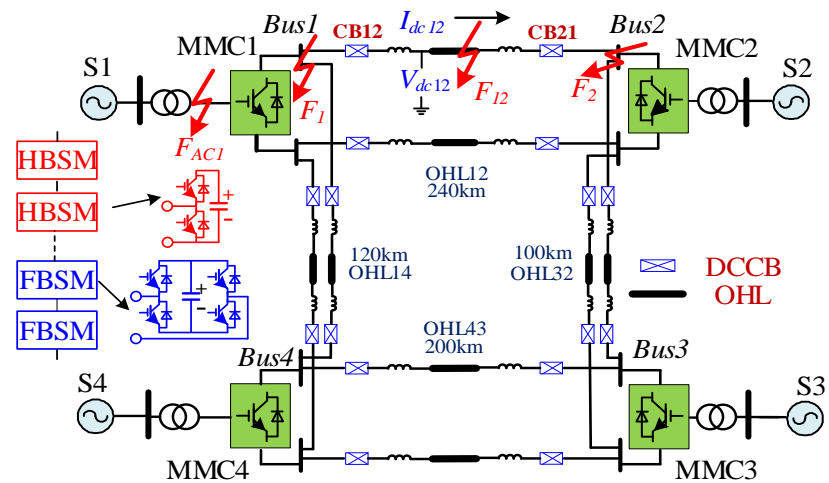

Fig. 13. The topology of a four-terminal hybrid MMC based DC grid.

\section{A. Determination of Thresholds}

Taking the relay CB12 as an example, the threshold setting calculation will be conducted as follows. Regarding the selection of reliability coefficients, for increment protection algorithms, such as ground instantaneous overcurrent protection, the reliability coefficient is ranging from 1.25 to 1.5 [26]. For decrement protection algorithms, such as the protection zone $I$ of distance protection, the reliability coefficient is ranging from 0.8 to 0.9 [26]. To improve the reliability to avoid mal-operation, the reliability coefficients are selected to be 1.5 for increment protection criterion while 0.8 for decrement protection criterion.

\section{1) Threshold setting $\Delta_{I}$ for Stage I protection}

The ROCOV with a lower threshold $\Delta_{I}$ is employed to detect low-impedance faults as Stage I protection. Thus, the threshold $\Delta_{I}$ should be much smaller than the measured ROCOV under the most severe external fault that happens at the DC terminal of MMC2 $\left(F_{2}\right)$.

Generally, the noise disturbance will increase the amplitude of the ROCOV. To avoid false-operation under external faults, an external fault $F_{2}$ with $20 \mathrm{~dB}$ noise disturbance has been considered to determine the threshold $\Delta_{I}$. The specific process of the threshold determination is presented as follows:

1) The ROCOV under the most severe external fault case $\left(F_{2}, 0.01 \Omega\right)$ is measured: $\mathrm{ROCOV}=-1093 \mathrm{kV} / \mathrm{ms}$.

2) A high reliability coefficient $\left(k_{\text {rell }}=1.5\right)$ is adopted to make sure that the protection scheme will not be falsely triggered under the most severe external faults with noise disturbance: $\Delta_{I}=1.5 \times(-1093)=-1640 \mathrm{kV} / \mathrm{ms}$.

\section{2) Threshold setting $\Delta_{I I}$ for the start-up element}

The ROCOV with a higher threshold $\Delta_{I I}$ is employed to trigger the following Stage II protection. Thus, the threshold $\Delta_{I I}$ (negative) should be larger than the measured ROCOV under all internal faults. To avoid false activation caused by noise disturbance under the normal state, the threshold $\Delta_{I I}$ should be smaller than the measured ROCOV under normal state. Based on the aforementioned principle, scan different positive pole-to-ground (P-PTG) DC faults with $500 \Omega$ fault resistance along OHL12 to obtain the measured ROCOV, as shown in Table 3.

Table 3 Measured ROCOVs under different internal P-PTG faults with $500 \Omega$ resistance $(\mathrm{kV} / \mathrm{ms})$

\begin{tabular}{c||c|c|c|c|c}
\hline $\begin{array}{c}\text { Fault } \\
\text { locations }\end{array}$ & $\begin{array}{c}\text { 0\% of } \\
\text { OHL12 }\end{array}$ & $\begin{array}{c}25 \% \text { of } \\
\text { OHL12 }\end{array}$ & $\begin{array}{c}50 \% \text { of } \\
\text { OHL12 }\end{array}$ & $\begin{array}{c}75 \% \text { of } \\
\text { OHL12 }\end{array}$ & $\begin{array}{c}100 \% \text { of } \\
\text { OHL12 }\end{array}$ \\
\hline \hline ROCOV & -1038 & -1067 & -920 & -780 & -912 \\
\hline
\end{tabular}

As shown in Table 3, the maximum value of $R O C O V$ is -
$780 \mathrm{kV} / \mathrm{ms}$. In the simulations, the $d V_{d c_{-} \text {line }} / \mathrm{dt}$ (negative) caused by $20 \mathrm{~dB}$ noise disturbance under normal state is larger than $400 \mathrm{kV} / \mathrm{ms}$. To avoid noise disturbance under the normal state, the reliability coefficient $k_{\text {rel2 }}$ is selected as 0.8 . The threshold $\Delta_{I I}$ can be obtained: $\Delta_{I I}=0.8 \times(-780)=-625 \mathrm{kV} / \mathrm{ms}$.

3) Threshold setting $\Delta V_{\text {set }}$ for Stage II protection

Applying P-PTG faults at $F_{2}$ with different fault resistances, the measured ROCOV and $\Delta V_{f}$ are shown in Fig. 14.

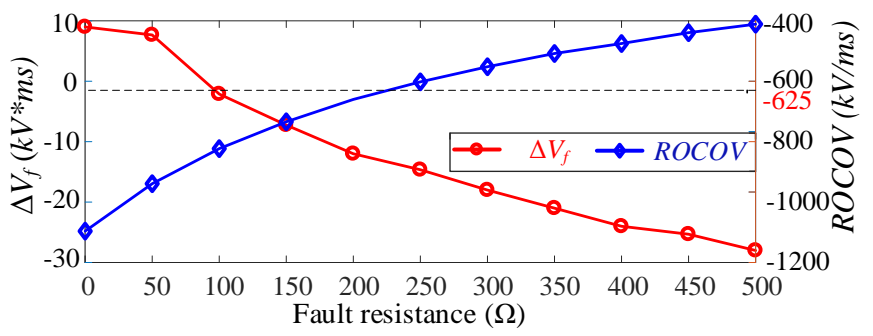

Fig. 14. The measured ROCOV and $\Delta V_{f}$ under DC faults at $F_{2}$ with different resistances.

In Fig. 14, with the increase of fault resistance, ROCOV increases while $\Delta V_{f}$ decreases. When the fault resistance exceeds $250 \Omega$, ROCOV is larger than the threshold $\Delta_{I I}$, which will not activate Stage II protection. Thus, the measured $\Delta V_{f}$ under DC fault with $500 \Omega$ resistance at $F_{2}$ is employed to calculate the threshold $\Delta V_{\text {set }}$. When the reliability coefficient $k_{\text {rel }}$ is selected as 1.5 and the threshold $\Delta V_{\text {set }}$ can be obtained: $\Delta V_{\text {set }}=1.5 \times(-28) \approx-45 k V^{*} m s$.

\section{4) The selection of the forward-feedback control coefficient} $K_{F F}$

Regarding the selection of the forward-feedback coefficient $K_{F F}$, the response of ACLC to DC fault and the stability of the current-limiting controller should be considered. A larger coefficient $K_{F F}$ will bring about a faster response of ACLC to DC faults. However, the coefficient $K_{F F}$ is restricted by the stability of the current-limiting controller. With the increase of the coefficient $K_{F F}$, the phase margin (PM) decreases, which weakens the stability.

Based on the Bode diagram analysis of DC current control loop, the phase margins (PM) under different coefficients $K_{F F}$ can be calculated, as shown in Table 4 .

Table 4 The measured $P M s$ under different coefficients $K_{F F}$

\begin{tabular}{c||c|c|c|c}
\hline$K_{F F}$ & 0.1 & 0.3 & 0.5 & 0.7 \\
\hline \hline$P M$ & $53.9^{\circ}$ & $49^{\circ}$ & $46.3^{\circ}$ & $44.1^{\circ}$ \\
\hline
\end{tabular}

To obtain good dynamic performances, the phase margin is suggested to range from $45^{\circ}$ to $60^{\circ}$. Thus, the coefficient $K_{F F}$ is suggested to range from 0 to 0.5 . To be conservative, the coefficient $K_{F F}$ is selected to be 0.3 .

\section{B. Simulation Analysis under Internal Faults}

\section{1) Response to a metallic P-PTG fault}

At $2.0 \mathrm{~s}$, a solid positive pole-to-ground fault is applied at $25 \%$ of OHL12 and the simulation waveforms are shown in Fig. 15.

As shown in Fig. 15(a), the initial backward TW $V_{b}^{l}$ arrives at $2.0002 \mathrm{~s}$, resulting in the rapid drop of the DC line voltage $V_{d c 12 p}$. The measured ROCOV is smaller than the threshold $\Delta_{I}$ $(-1640 \mathrm{kV} / \mathrm{ms})$, as shown in Fig. 15(b). Thus, it is deemed to be an internal fault and the detection time is no more than $0.3 \mathrm{~ms}$. 


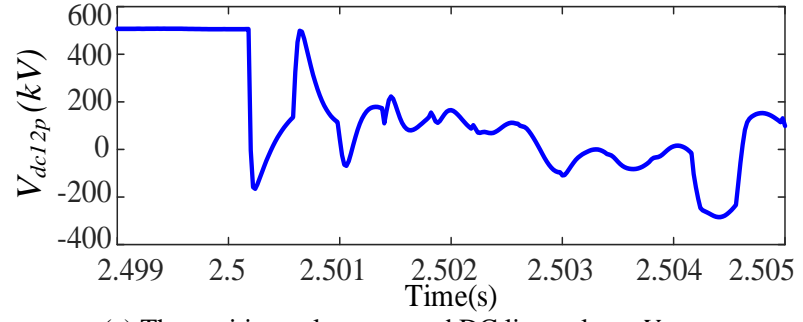

(a) The positive pole-to-ground DC line voltage $V_{d c 12 p}$

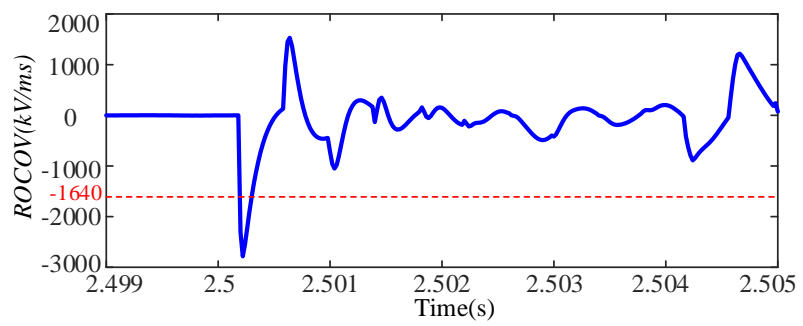

(b) ROCOV

Fig. 15. Simulation waveforms under a metallic internal P-PTG fault.

2) Response to a P-PTG fault with $400 \Omega$ fault resistance

At 2.0 s, a P-PTG fault with $400 \Omega$ fault resistance is applied at $25 \%$ of OHL12 and the simulation waveforms are shown in Fig. 16.

As can be seen in Fig. 16 (a), the DC line voltage drops rapidly at 2.002s. In Fig. 16(b), the measured ROCOV is larger than the threshold $\Delta_{I}(-1640 \mathrm{kV} / \mathrm{ms})$ while smaller than threshold $\Delta_{I I}(-625 \mathrm{kV} / \mathrm{ms})$, leading to the activation of the fault start-up element. The minimum values of the measured $d V_{b}^{l} / d t$ and $d V_{f}^{l} / d t$ are $-318.62 \mathrm{kV} / \mathrm{ms}$ and $-286.42 \mathrm{kV} / \mathrm{ms}$ respectively. $\min \left(d V_{b}^{l} / d t\right) / \min \left(d V_{f}^{l} / d t\right)=1.11>1$, which demonstrates that it is an internal forward fault. In Fig. 16 (c), the measured $\Delta V_{f}$ is smaller than the threshold $\Delta V_{\text {set }}\left(-45 k V^{*} m s\right)$, satisfying the criterion of the Stage II protection. Thus, it is identified to be an internal fault and the DCCB12 is tripped at $2.5057 \mathrm{~s}$, as shown in Fig. 16 (d).

In Fig. 16 (e), the maximum of the line current $I_{d c 12 p}$ is no more than $1.8 \mathrm{kA}$ (twice of the rated line current), indicating that there is no overcurrent. In addition, the ACLC can decrease the fault current before the DCCB12 is tripped. Thus, the breaking capacity of the DCCBs is decreased.

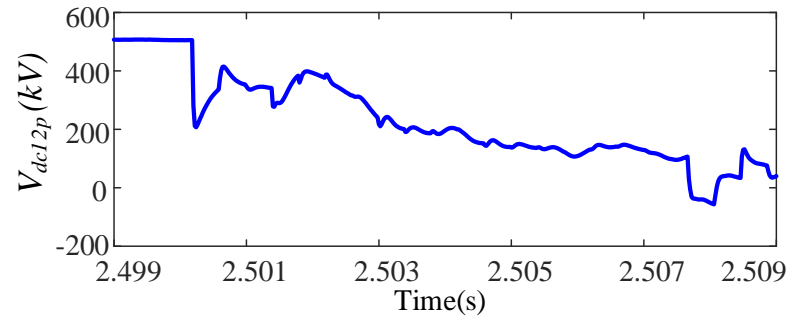

(a) The positive pole-to-ground DC line voltage $V_{d c 12 p}$

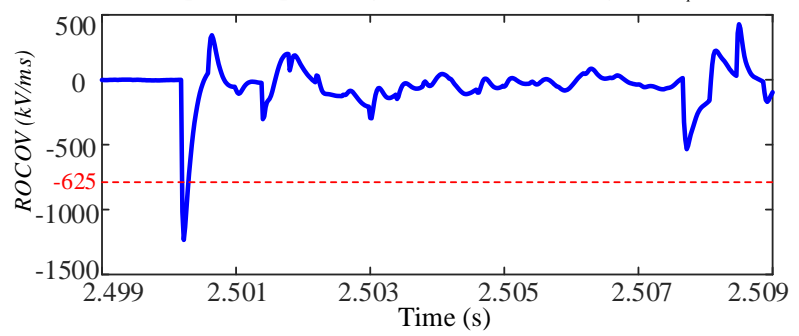

(b) ROCOV

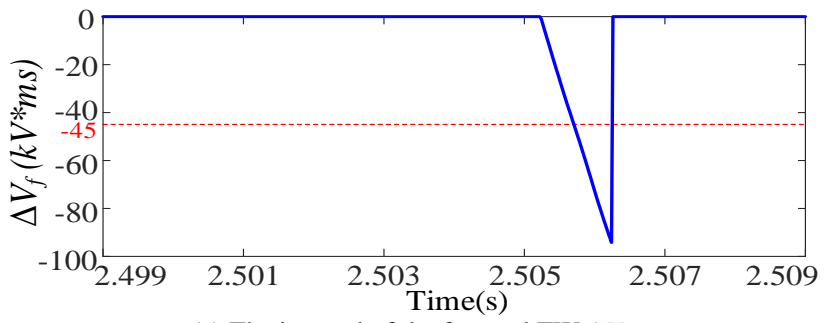

(c) The integral of the forward TW $\Delta V_{f}$

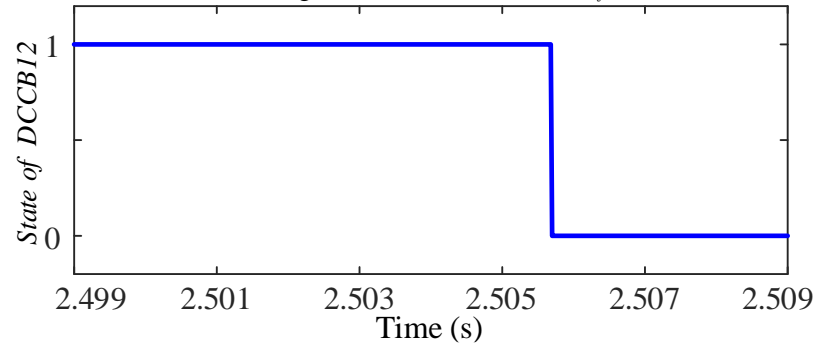

(d) The state of DCCB12

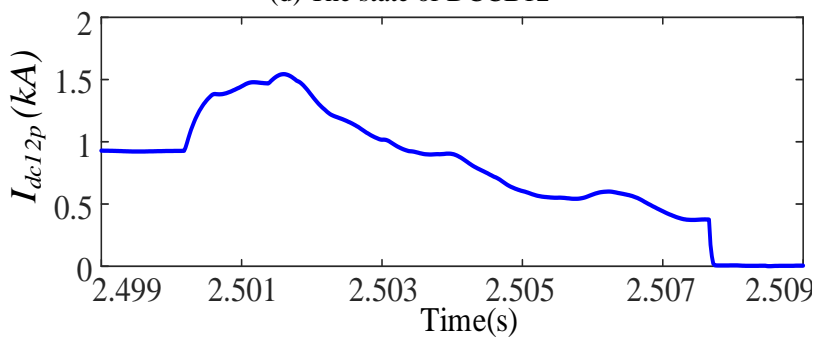

(e) The DC line current $I_{d c 12 p}$

Fig. 16. Simulation waveforms under a P-PTG fault with $400 \Omega$ resistance.

\section{Simulation Analysis under External Faults}

1) Response to a bus fault

At 2.0s, a solid P-PTG fault is applied at the Bus2 $\left(F_{2}\right)$ and the simulation waveforms are shown in Fig. 17.

As can be seen in Fig. 17 (a), the measured ROCOV is smaller than the threshold $\Delta_{I I}(-625 \mathrm{kV} / \mathrm{ms})$, triggering the fault start-up element. In Fig. 17 (b), the measured $\Delta V_{f}$ is larger than the threshold $\Delta V_{\text {set }}\left(-45 k V^{*} m s\right)$, which does not satisfy the criterion of the Stage II protection. Thus, the fault is deemed to be external. Fig. 17 demonstrates that the proposed method can identify internal and external faults correctly.

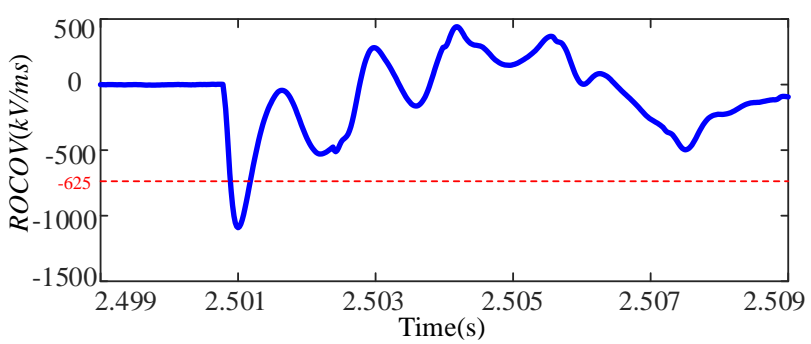

(a) ROCOV

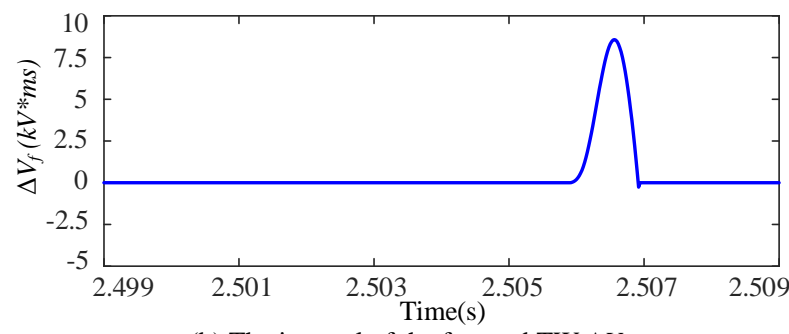

(b) The integral of the forward TW $\Delta V_{f}$

Fig. 17. Simulation waveforms under an external P-PTG fault. 
2) Response to external faults on the OHL14 and OHL23

More solid P-PTG faults are applied in the middle of the OHL14 and OHL23 respectively to test the effectiveness under external faults. The simulation waveforms are shown in Fig. 18 and Fig. 19.

As can be seen in Fig. 18, the measured ROCOV is larger than threshold $\Delta_{I I}(-625 \mathrm{kV} / \mathrm{ms})$, which will not trigger the fault start-up element. Thus, the fault on the OHL14 is identified to be external.

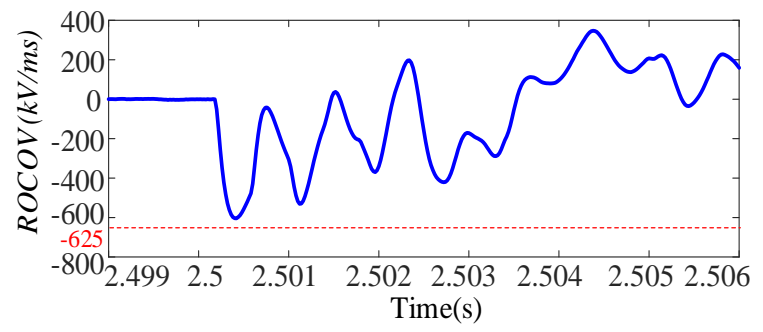

Fig. 18. Simulation waveform in the case of a fault in the middle of OHL14.

In Fig. 19(a), the measured ROCOV is smaller than threshold $\Delta_{I I}(-625 \mathrm{kV} / \mathrm{ms})$, activating the fault start-up element. In Fig. 19(b), $\Delta V_{f}$ is larger than the threshold $\Delta V_{\text {set }}\left(-45 k V^{*} m s\right)$, which does not satisfy the criterion of the Stage II protection. Hence, the fault on the OHL23 is deemed to be external.

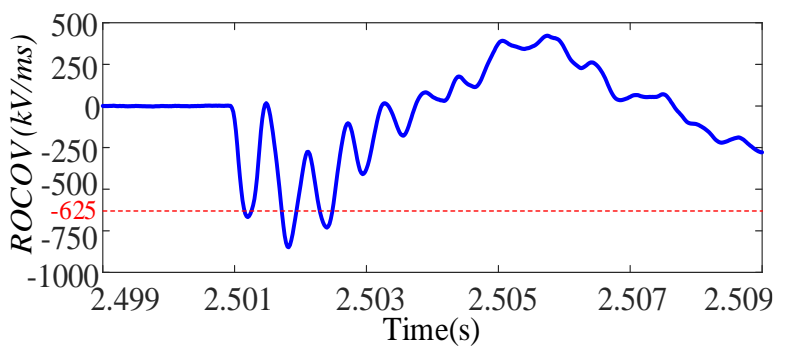

(a) ROCOV

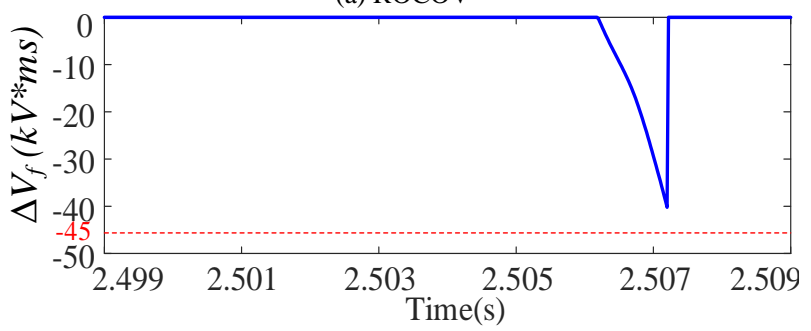

(b) The integral of the forward TW $\Delta V_{f}$

Fig. 19. Simulation waveforms in the case of a fault in the middle of OHL32.

In the case of external line faults, such as the faults on the OHL32 and OHL14, the sharp negative voltage TW induced from the fault point will be smoothed by multiple currentlimiting reactors. Thus, for relay CB12, the amplitude of the measured ROCOV is smaller, Hence, the Stage I protection will not be activated, neither the fault start-up element, as shown in Fig. 18 and Fig. 19. To be concluded, the external line faults can be identified correctly.

\section{ROBUSTNESS ANALYSIS}

\section{A. Impacts of Fault Resistance}

At 2.0s, various P-PTG faults with different resistances varying from $50 \Omega$ to $500 \Omega$ are applied at the end of OHL12 (close to MMC2) to test the impacts of fault resistances. The simulation waveforms are shown in Fig. 20.

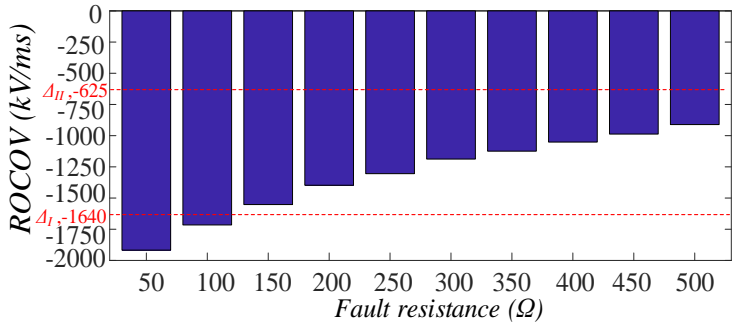

(a) ROCOV

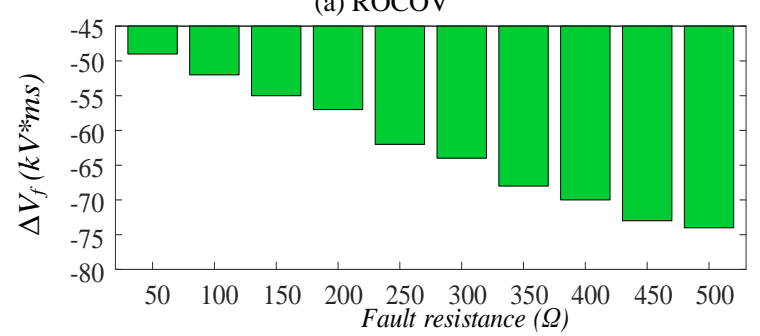

(b) The integral of the forward TW $\Delta V_{f}$

Fig. 20. The measured ROCOVs and $\Delta V_{f}$ under various fault resistances

As can be seen in Fig. 20(a), when the fault resistance increases to $100 \Omega$, the ROCOV will be larger than the threshold $\Delta_{I}$. However, the measured $\Delta V_{f}$ is still smaller than the threshold $\Delta V_{\text {set }}\left(-45 k V^{*} m s\right)$, which demonstrates that the proposed method is endurable to large fault resistances. The maximum fault resistance that the proposed method can identify is up to $500 \Omega$.

\section{B. Influence of Noise}

To test the robustness of the noise disturbance, a $20 \mathrm{~dB}$ white noise is added into the measured voltages $V_{d c 12 p}$ and $V_{f}$. Then, at $2.5 \mathrm{~s}$, a solid P-PTG fault is applied at the DC bus $\left(F_{2}\right)$. The simulation waveforms are shown in Fig. 21.

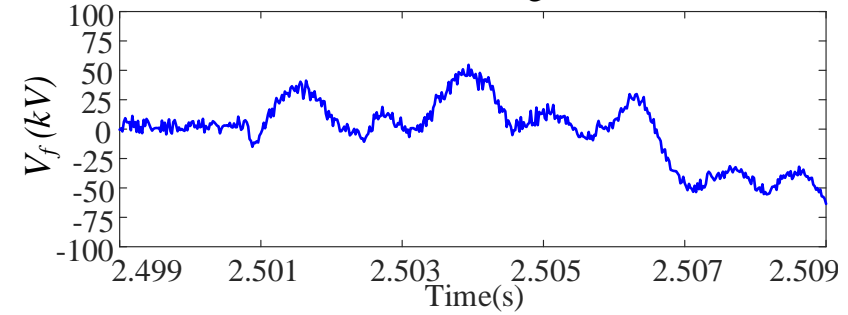

(a) the forward TW $V_{f}$

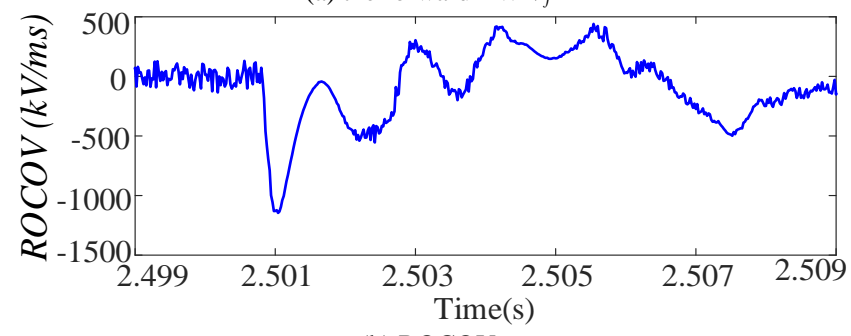

(b) ROCOV

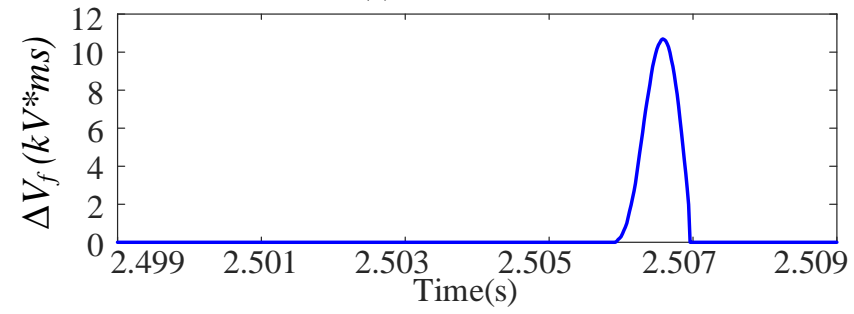

(c) The integral of the forward TW $\Delta V_{f}$

Fig. 21. Simulation waveforms under an internal fault with $20 \mathrm{db}$ noise.

During the determination of threshold $\Delta_{I}$, a large reliability coefficient $k_{\text {rell }}$ is adopted to guarantee high selectivity. Thus, 
the measured ROCOV with $20 \mathrm{~dB}$ noise is larger than the threshold $\Delta_{I}$, which will not lead to the false operation of the Stage I protection. However, the measured ROCOV is smaller than the threshold $\Delta_{I I}$, triggering the fault start-up element, as shown in Fig. 21 (a).

The average value of the noise signal is equal to zero. Thus, the integral method is employed to mitigate the impacts of the noise. As can be seen in Fig. 21(b), the measured $\Delta V_{f}$ is larger than the threshold $\Delta V_{\text {set. }}$. Thus, it is identified to be external. To be concluded, the proposed method is robust to noise.

\section{The Applicability of the Pole-to-pole Faults.}

Based on the aforementioned principle of the threshold determination, the threshold $\Delta V_{\text {set }}$ for PTP faults is adopted as $184 \mathrm{kV}^{*} \mathrm{~ms}$. Various PTP faults are applied to test the applicability of the proposed method for the PTP faults, as shown in Table 5.

As can be been in Table 5, the proposed method can be employed to detect PTP faults correctly. Compared with PTG faults, the amplitude of the $d V_{d c \text { line }} / d t$ is larger than that under PTP faults. Thus, the Stage I protection is activated faster under internal PTP faults.

\section{Discussions and Comparisons}

1) The impacts of the change of the operation mode

As pointed out in [27], in the case of the operation mode changes, such as the power reversal, the DC line voltage has a small fluctuation, which will not trigger the fault start-up element. Thus, the change of the operation mode has no impacts on the proposed method

2) The Response to AC faults

In the event of the most severe $\mathrm{AC}$ fault, the DC line voltage has a small fluctuation, due to the independent control between the AC side and DC side. The fault start-up element will not be activated. To be concluded, the proposed method will not be affected by AC faults.

Table 5 Simulation results under different PTP faults

\begin{tabular}{|c|c|c|c|c|}
\hline Fault Location & Fault resistance $(\Omega)$ & $d V_{d c 12 p} / \mathrm{dt}$ & $\Delta V_{f}$ & Fault identification \\
\hline \multirow{4}{*}{$\begin{array}{l}0 \% \text { of OHL12 } \\
\text { (close to MMC1) }\end{array}$} & 0.01 & $22297<\Delta_{I}$ & \multirow{2}{*}{ l } & \multirow{2}{*}{$\begin{array}{c}\text { Stage I protection is activated and it is } \\
\text { deemed to be an internal fault }\end{array}$} \\
\hline & 200 & $1771<\Delta_{I}$ & & \\
\hline & 300 & $\Delta_{I}<1590<\Delta_{I I}$ & $153<\Delta V_{\text {set }}$ & \multirow{2}{*}{$\begin{array}{l}\text { Stage II protection is activated and it is } \\
\text { deemed to be an internal fault }\end{array}$} \\
\hline & 500 & $\Delta_{I}<1319<\Delta_{I I}$ & $59<\Delta V_{\text {set }}$ & \\
\hline \multirow{4}{*}{$50 \%$ of OHL 12} & 0.01 & $-3828<\Delta_{I}$ & \multirow{3}{*}{ / } & \multirow{3}{*}{$\begin{array}{l}\text { Stage I protection is activated and it is } \\
\text { deemed to be an internal fault }\end{array}$} \\
\hline & 200 & $-2487<\Delta_{I}$ & & \\
\hline & 300 & $-2116<\Delta_{I}$ & & \\
\hline & 500 & $\Delta_{I}<-1627<\Delta_{I I}$ & $53<\Delta V_{\text {set }}$ & $\begin{array}{l}\text { Stage II protection is activated and it is } \\
\text { deemed to be an internal fault }\end{array}$ \\
\hline \multirow{4}{*}{$\begin{array}{l}100 \% \text { of OHL12 } \\
\text { (close to MMC2) }\end{array}$} & 0.01 & $-3473<\Delta_{I}$ & \multirow{4}{*}{ l } & \multirow{4}{*}{$\begin{array}{l}\text { Stage I protection is activated and it is } \\
\text { deemed to be an internal fault }\end{array}$} \\
\hline & 200 & $-2645<\Delta_{I}$ & & \\
\hline & 300 & $-2363<\Delta_{I}$ & & \\
\hline & 500 & $-1947<\Delta_{I}$ & & \\
\hline \multirow{4}{*}{ The Bus2 $\left(F_{2}\right)$} & 0.01 & $\Delta_{I}<-1004<\Delta_{I I}$ & $503>\Delta V_{\text {set }}$ & \multirow{4}{*}{$\begin{array}{l}\text { Neither Stage I nor Stage II Protection is } \\
\text { activated and it is deemed to be an } \\
\text { external fault }\end{array}$} \\
\hline & 50 & $\Delta_{I}<-834<\Delta_{I I}$ & $379>\Delta V_{\text {set }}$ & \\
\hline & 150 & $\Delta_{I}<-641<\Delta_{I I}$ & $300>\Delta V_{\text {set }}$ & \\
\hline & 200 & $-577>\Delta_{I I}$ & 1 & \\
\hline
\end{tabular}

Table 6 Comparison between the proposed method and some typical methods without the impacts of ACLC

\begin{tabular}{|c|c|c|c|c|c|}
\hline \multicolumn{2}{|c|}{ Protection schemes } & $\begin{array}{c}\text { Endurance to fault } \\
\text { resistance } / \Omega\end{array}$ & $\begin{array}{c}\text { Resistance to } \\
\text { noise/dB }\end{array}$ & $\begin{array}{c}\text { Sampling } \\
\text { frequency } / \mathrm{kHz}\end{array}$ & Other drawbacks \\
\hline \multirow{7}{*}{$\begin{array}{l}\text { without considering } \\
\text { the impacts of } \\
\text { ACLC }\end{array}$} & $\begin{array}{l}{[21]} \\
{[22]}\end{array}$ & weak & " & $\begin{array}{c}100 \\
/\end{array}$ & / \\
\hline & {$[27]$} & \multirow{5}{*}{$\sqrt{ }$} & weak & 200 & \multirow{2}{*}{ Close-in faults are difficult to be detected } \\
\hline & [14] & & $\times$ & 100 & \\
\hline & {$[28]$} & & weak & $\sqrt{ }$ & \multirow{2}{*}{$\begin{array}{l}\text { WT mother function and sampling } \\
\text { frequency are difficult to be selected }\end{array}$} \\
\hline & $\begin{array}{l}{[25]} \\
{[19]}\end{array}$ & & \multirow{3}{*}{$\sqrt{ }$} & 1000 & \\
\hline & {$[16]$} & & & 200 & 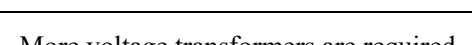 \\
\hline & [17] & 200 & & $\sqrt{ }$ & More voltage transformers are required \\
\hline \multicolumn{2}{|l|}{ The proposed meth } & \multicolumn{3}{|c|}{$\sqrt{ }$} & 1 \\
\hline
\end{tabular}

\section{3) Comparison with other protections}

A comprehensive comparison between the proposed method and other protection schemes without considering the impacts of ACLC has been conducted, as shown in Table 6. Where "ل/" means that the maximum resistance that can be identified is $\geq 300 \Omega$, the sampling frequency is $\leq 50 \mathrm{kHz}$, and the noise that can be endured is stronger than $20 \mathrm{~dB}$. Otherwise, the relevant technology is noted as " $\times$ ".

As can be seen in Table 6, the proposed method has significant advantages on the robustness against fault resistance and noise disturbance. In addition, a lower sampling frequency is adopted. Among these protections without the impacts of ACLC, for WT based methods, the cascaded filtering and multi-scale decomposition will lead to a higher sampling-frequency and a heavier computation burden. For reactor voltage-based methods, they are vulnerable to resistance or noise.

Moreover, a detailed simulation is conducted to test the performances of the proposed method in [21]. The criterion for the discrimination of internal and external faults in [21] is:

$$
\left\{\begin{array}{c}
\frac{d V_{d c}}{d t}<T h 1 \text { and } \frac{d I_{d c}}{d t}>T h 2 \\
V_{d c}\left(t_{d e t}+\Delta t_{d i s c r}\right)<T h 3
\end{array}\right.
$$


where the under-voltage criterion is achieved by monitoring the voltage with a defined period of time $\Delta t_{\text {discr }}(100 \mu \mathrm{s})$ after the start-up element is activated. The time when the start-up element is activated is defined as $t_{\text {det }}$.

A solid PTG fault with 20dB noise is applied at the Bus2 $\left(F_{2}\right)$ and a PTG fault with $300 \Omega$ resistance is applied at the end of OHL12 $\left(F_{12}\right)$.

The measured ROCOVs are respectively $-1140 \mathrm{kV} / \mathrm{ms}$ for the fault $F_{2}$ and $-1206 \mathrm{kV} / \mathrm{ms}$ for the fault $F_{12}$, as shown in Fig. 21 (b) and Fig. 22 (a). The DC line voltages at the time $t_{d e t}+\Delta t_{\text {discr }}$ are respectively $161 \mathrm{kV}$ for the fault $F_{12}$ and $133 \mathrm{kV}$ for the fault $F_{2}$, as shown in Fig. 22 (b) and Fig. 23. The lowvoltage criterion in (29) does not hold true, which demonstrates that the proposed method in [21] is vulnerable to fault resistance and noise disturbance.

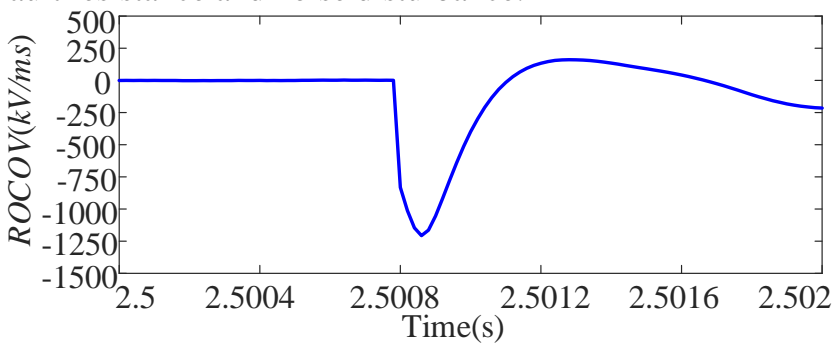

(a) ROCOV

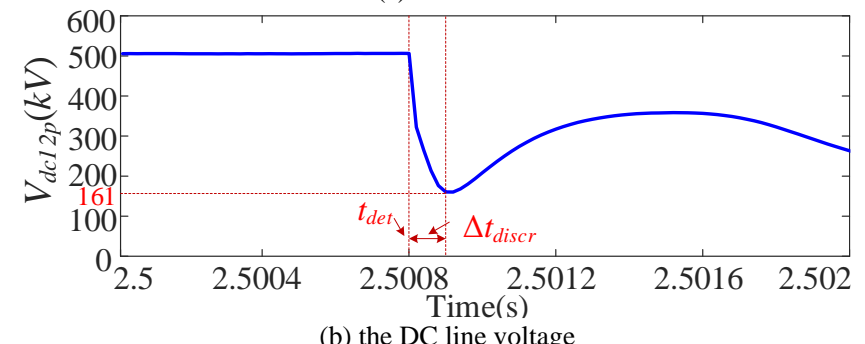

Fig. 22. Simulations under the internal fault with $300 \Omega$ resistance $\left(F_{12}\right)$.

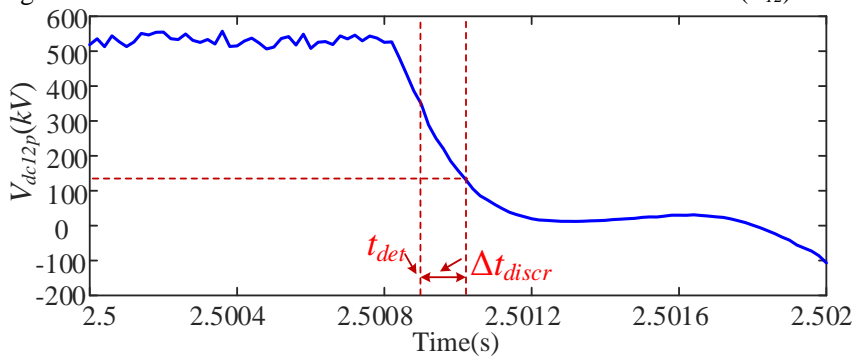

Fig. 23. DC line voltage under the solid external fault with $20 \mathrm{~dB}$ noise $\left(F_{2}\right)$.

\section{CONCLUSION}

For the hybrid MMC based DC grids, a single-end protection scheme that considers the impacts of the ACLC is proposed to achieve selective fault detection. The impacts of the ACLC on TW characteristics under different stages are evaluated and the differences of forward TWs under different fault locations are analyzed. Based on the analysis, it can be concluded:

1) The ACLC will actively reduce the MMC output DC voltage, which is equivalent to injecting a negative forward TW into the transmission lines. The impacts of the ACLC on forward TWs under internal faults are greater than those under external faults. Thus, the low-voltage criterion of the forward TW is employed to design the criterion.

2) The proposed method can identify faults with fault resistance as high as $500 \Omega$ and it is immune to noise with $20 \mathrm{~dB}$. In addition, the method is not affected by the changes of the operation mode, fault distances and $\mathrm{AC}$ faults.

3) In comparison with schemes of HB MMC based DC grids, such as ROCOV, WT based methods and so on, the proposed method has advantages on the capability of the robustness to high-resistance and noise disturbance. Besides, a lower sampling frequency and computation burden is adopted.

The proposed method provides a systematical approach for the protection design of fault-tolerant MMCs with fault current-limiting capability.

\section{APPENDIX}

The overhead transmission lines are modeled based on the frequency-dependent (phase) model of the PSCAD/EMTDC. Fig. 24 illustrates the configuration of the DC overhead transmission line.

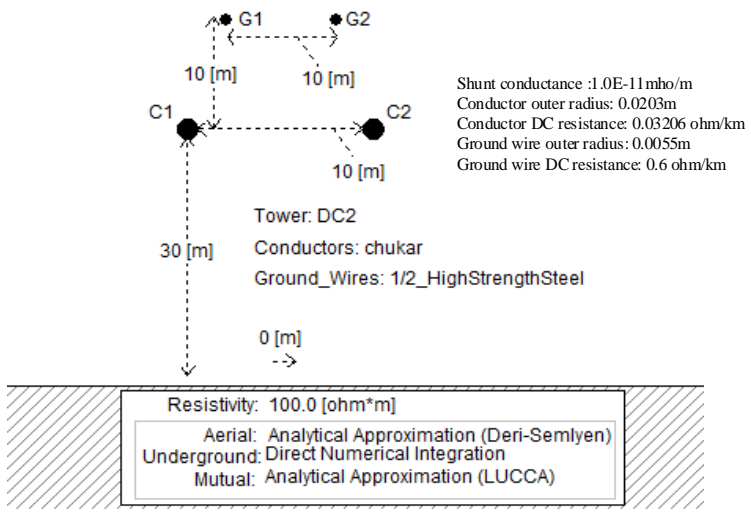

Fig. 24. Configuration of the overhead lines.

\section{REFERENCES}

[1] S. Yang, W. Xiang, X. Lu, et al., "An Adaptive Reclosing Strategy for MMC-HVDC Systems with hybrid DC Circuit Breakers," IEEE Trans. Power Del., early access, to be published.

[2] G. Li, T. An, J. Liang, et al., "Power reversal strategies for hybrid LCC/MMC HVDC systems," CSEE Journal of Power and Energy Syst., vol. 6, no. 1, pp. 203-212, Mar. 2020.

[3] J. He, K. Chen, M. Li, et al., "Review of protection and fault handling for a flexible DC grid," Prot. Control Mod. Power Syst., vol. 5, no. 15, pp. 1-15, May 2020.

[4] W. Xiang, S. Yang and J. Wen, "ANN-based robust DC fault protection algorithm for MMC high-voltage direct current grids," IET Renew. Power Gener., vol. 14, no. 2, pp. 199-210, Feb. 2020.

[5] W. Xiang, W. Lin, T. An, et al, "Equivalent Electromagnetic Transient Simulation Model and Fast Recovery Control of Overhead VSC-HVDC Based on SB-MMC," IEEE Trans. Power Del., vol. 32, no. 2, pp. 778788, Apr. 2017.

[6] R. Marquardt, "Modular multilevel converter: An universal concept for HVDC-networks and extended DC-bus-applications," in Proc. IPEC, 2010, pp. 502-507.

[7] W. Lin, D. Jovcic, S. Nguefeu, et al., "Full-Bridge MMC Converter Optimal Design to HVDC Operational Requirements," IEEE Trans. Power Del., vol. 31, no. 3, pp. 1342-1350, June 2016.

[8] W. Xiang, W. Lin, L. Xu, et al., "Enhanced Independent Pole Control of Hybrid MMC-HVDC System," IEEE Trans. Power Del., vol. 33, no. 2, pp. 861-872, Apr. 2018.

[9] J. Hu, K. Xu, L. Lin, et al., "Analysis and Enhanced Control of HybridMMC-Based HVDC Systems during Asymmetrical DC Voltage Faults," IEEE Trans. Power Del., vol. 32, no. 3, pp. 1394-1403, June 2017.

[10] M. Zhou, W. Xiang, W. Zuo, et al., "Active Current-Limiting Control to Handle DC Line Fault of Overhead DC Grid," 2019 10th International Conference on Power Electronics and ECCE Asia (ICPE 2019 - ECCE Asia), Busan, Korea (South), 2019, pp. 1-6. 
[11] D. Jovcic, W. Lin, S. Nguefeu, et al., "Low-Energy Protection System for DC Grids Based on Full-Bridge MMC Converters," IEEE Trans. Power Del., vol. 33, no. 4, pp. 1934-1943, Aug. 2018.

[12] N. Jin, X. Lin, J. Xing, et al., "Research on Multiterminal Current Differential Protection Criterion with High Sensitivity and Synchronization Error Tolerance Capability," IEEE Trans. Power Del., vol. 33, no. 6, pp. 3085-3094, Dec. 2018.

[13] M. Kong, X. Pei, H. Pang, J. Yang, et al., “A Lifting Wavelet-based Protection Strategy against DC Line Faults for Zhangbei HVDC Grid in China," presented in 19 th European Conf. on Power Electron. And Applica. (EPE'17 ECCE Europe), Warsaw, Poland, Sep. 2017, pp. 1-11.

[14] Q. Huang, G. Zou, X. Wei, et al., "A Non-unit Line Protection Scheme for MMC-based Multi-terminal HVDC grid," Int. J. Elect. Power Energy Syst., vol. 107, pp. 1-9, 2019.

[15] S. Zhang, G. Zou, Q. Huang, et al, "Single-ended Line Protection for MMC-MTDC Grids," IET Gener. Transm. Distrib., vol. 13, no. 19, pp.4331-4338, Aug. 2019.

[16] R. Li, L. Xu, L. Yao, "DC Fault Detection and Location in Meshed Multi-terminal HVDC Systems based on DC Reactor Voltage Change Rate," IEEE Trans. Power Del., vol.32, no.3, pp. 1516-1626, Jun. 2017.

[17] S. Yang, W. Xiang, R. Li, et al., "An Improved DC fault Protection Algorithm for MMC HVDC Grids based on Modal Domain Analysis," IEEE Journal of Emerging and Selected Topics in Power Electron., early access, doi: 10.1109/JESTPE.2019.2945200.

[18] C. Li, A. M. Gole, C. Zhao, "A Fast DC Fault Detection Method Using DC Reactor Voltages in HVdc Grids," IEEE Trans. Power Del., vol. 33, no. 5, pp. 2254-2264, Oct. 2018.

[19] L. Tang, X. Dong, S. Shi, et al., "A High-speed Protection Scheme for the DC Transmission Line of a MMC-HVDC Grid," Elect. Power Syst. Research, vol. 168, pp. 81-91, 2019.

[20] J. Liu, N. Tai and C. Fan, "Transient-Voltage-Based Protection Scheme for DC Line Faults in the Multiterminal VSC-HVDC System," IEEE Trans. Power Del., vol. 32, no. 3, pp. 1483-1494, June 2017.

[21] W. Leterme, J. Beerten, D. V. Hertem, "Nonunit protection of HVDC grids with inductive DC cable termination", IEEE Trans. Power Del., vol. 31, pp. 820-828, Apr. 2016.

[22] J. Sneath, A. Rajapakse, "Fault detection and Interruption in an earthed HVDC grid using ROCOV and hybrid DC breakers," IEEE Trans. Power Del., vol.31, no.3, pp. 973-981, Jun. 2016.

[23] J. Zhang, C. Y. Chung and L. Guan, "Noise Effect and Noise-Assisted Ensemble Regression in Power System Online Sensitivity Identification," IEEE Trans. Ind. Informat., vol. 13, no. 5, pp. 23022310, Oct. 2017.

[24] J. Häfner, B. Jacobson, "Proactive Hybrid HVDC Breakers-A key innovation for reliable HVDC grids," CIGRE Session, Italy, Bologna: CIGRE, 2011:1-8.

[25] M. Abedrabbo, W. Leterme and D. Van Hertem, "Systematic Approach to HVDC Circuit Breaker Sizing," IEEE Trans. Power Del. vol. 35, no. 1, pp.288-300, Feb. 2020.

[26] M. J. Thompson and D. L. Heidfeld, "Transmission line setting calculations - beyond the cookbook," $201568^{\text {th }}$ Annual Conference for Protective Relay Engineers, College Station, TX, 2015, pp. 850-865.

[27] W. Xiang, S. Yang, L. Xu, et al., "A Transient Voltage based DC Fault Line Protection Scheme for MMC based DC Grid Embedding DC Breakers," IEEE Trans. Power Del., vol. 34, no. 1, pp. 334-345, Feb. 2019

[28] S. Zhang, G. Zou, C. Wang, et al., "A Non-unit Boundary Protection of DC Line for MMC-MTDC Grids," Int. J. Elect. Power Energy Syst., vol. 116, pp. 1-9, 2019.

\section{BIOGRAPHIES}

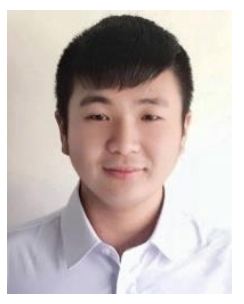

Saizhao Yang obtained his B.E. degree in electrical engineering from Huazhong University of Science and Technology (HUST), China, in 2018. He is currently pursuing his $\mathrm{PhD}$ degree at HUST. His research interests include dc fault protection of MMC-HVDC and dc grids.

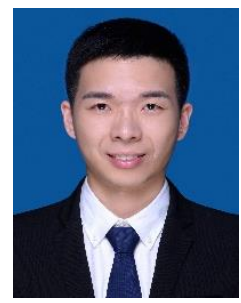

Wang Xiang (S'16-M'17) received his B.Eng. and $\mathrm{PhD}$ degrees both in electrical engineering from Huazhong University of Science and Technology (HUST), China in 2012 and 2017, respectively. He was a visiting student at the University of Aberdeen and the University of Strathclyde in 2014 and 2016 respectively. Currently, he is a research associate with the University of Strathclyde since 2018. His main research interests include MMC-HVDC, high power $\mathrm{dc} / \mathrm{dc}$ converters and dc grids.

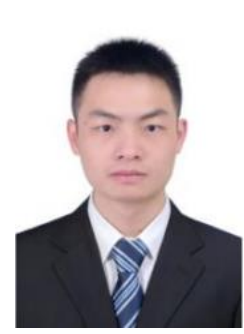

Meng Zhou was born in Hunan, China, in 1987. He received the $\mathrm{Ph} . \mathrm{D}$. degree in electrical engineering from the School of Electrical and Electronic Engineering, Huazhong University of Science and Technology, Hubei, China, in 2019. He is currently a Postdoctoral Researcher with the School of Electrical and Electronic Engineering, Huazhong University of Science and Technology. His current research interests include voltage-source converter-HVdc and dc circuit breaker.

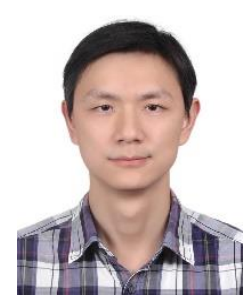

Wenping Zuo received the B.S. degree and Ph.D degree in electrical engineering from Huazhong University of Science and Technology (HUST), Wuhan, China, in 2009 and 2017, respectively. Currently, he is a Post-Doctoral Research Fellow with HUST. His research interests include DC grid key equipment, energy storage, and renewable energy integration.

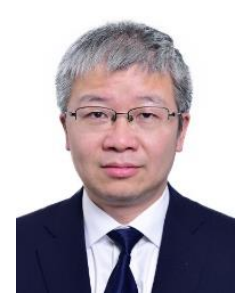

Jinyu Wen (M'10) received his B.Eng. and Ph.D. degrees all in electrical engineering from Huazhong University of Science and Technology (HUST), Wuhan, China, in 1992 and 1998, respectively. He was a visiting student from 1996 to 1997 and a research fellow from 2002 to 2003 all at the University of Liverpool, UK, and a senior visiting researcher at the University of Texas at Arlington, USA in 2010. From 1998 to 2002 he was a director engineer in XJ Electric Co. Ltd. in China. In 2003 he joined the HUST and now is a Professor at HUST. His current research interests include renewable energy integration, energy storage application, DC grid, and power system operation and control. 